\title{
Effect of Clupeonella grimmi (anchovy/kilka) fish oil on dysmenorrhoea
}

\author{
A.A. Moghadamnia, ${ }^{7}$ N. Mirhosseini, ${ }^{2}$ M. Haji Abadi, ${ }^{1}$ A. Omranirad ${ }^{7}$ and Sh. Omidvar ${ }^{1}$
}

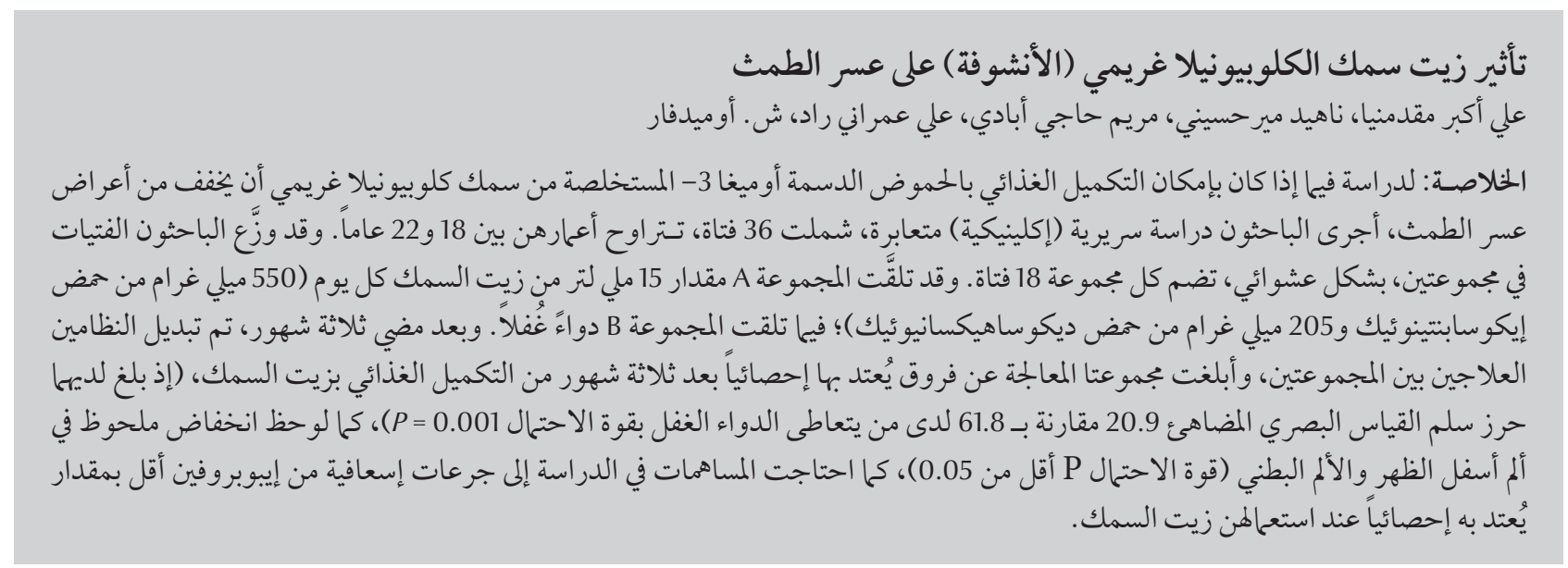

ABSTRACT To examine whether dietary supplementation with omega-3 fatty acids from Clupeonella grimmi can relieve symptoms of dysmenorrhoea, we carried out a cross-over clinical trial on 36 girls aged 18-22 years. They were randomly allocated into 2 groups of 18. Group A received $15 \mathrm{~mL}$ fish oil daily $(550 \mathrm{mg}$ eicosapentaenoic acid; 205 mg decosahexaenoic acid) while Group B received placebo. After 3 months, the treatment regimens were swapped. The treatment groups reported a significant difference after 3 months of supplementation with fish oil (visual analogue scale score 20.9 compared with 61.8 for the placebo $(P=0.001)$. There was also a marked reduction in low back pain and abdominal pain $(P<0.05)$, and participants needed significantly fewer rescue doses of ibuprofen while using fish oil.

\section{Effet de l'huile de Clupeonella grimmi (anchois/kilka) sur la dysménorrhée}

RÉSUMÉ Afin d'étudier si une supplémentation en acides gras oméga 3 provenant de Clupeonella grimmi peut soulager les symptômes de dysménorrhée, nous avons conduit une étude clinique croisée sur 36 filles âgées de 18 à 22 ans, réparties de manière aléatoire en deux groupes de 18. Le groupe $\mathrm{A}$ a reçu quotidiennement $15 \mathrm{ml}$ d'huile de poisson (550 mg d'acide eicosapentaénoïque ; 205 mg d'acide docosahexénoïque) alors que le groupe B était sous placebo. Au bout de trois mois, les schémas thérapeutiques ont été inversés. Les groupes bénéficiant du traitement ont montré une différence significative à l'issue de trois mois de supplémentation en huile de poisson (score d'échelle visuelle analogique 20,9 contre 61,8 pour le placebo $(P=0,001)$ ). Une diminution notable des douleurs abdominales et des douleurs dans le bas du dos a également été observée $(P<0,05)$, les participantes ayant eu nettement moins recours à des doses d'urgence d'ibuprofène lorsqu'elles prenaient de l'huile de poisson. 


\section{Introduction}

Dysmenorrhoea is one of the most frequent gynaecologic disorders, affecting more than half of menstruating women. With primary dysmenorrhoea, often begins $2-3$ years after menarche and lasts for several years, women have painful menses without demonstrable pelvic abnormality [1]. Symptoms may decrease after pregnancy [2]. Among female adolescents it is the most common gynaecologic complaint and the leading cause of recurrent short-term absenteeism $[3,4]$. The majority of dysmenorrhoea in adolescents is primary (or functional) and has a clear physiologic cause, with occasional psychological component $[3,5]$. Women with primary dysmenorrhoea have significantly higher concentrations of prostaglandin $(\mathrm{PG})$ in the endometrium and menstrual fluids than women without primary dysmenorrhoea $[1,6]$. The condition is treated by inhibiting prostaglandin synthesis with non-steroidal anti-inflammatory drugs (NSAIDs) $[7,8]$.

Omega-3 fatty acids, eicosapentaenoic and decosahexaenoic acids compete with omega- 6 fatty acids for the production of PGs and leukotrienes through incorporation into cell wall phospholipids and through competition at the prostaglandin synthetase level. In the uterus this competitive interaction between omega- 3 and omega- 6 fatty acid may result in the production of less potentPGs $[9,10]$ and leukotrienes [11]. Anchovy (also called kilka) (Chupeonella grimmi) is a common fish in the Caspian Sea. The oil is rich in omega-3 fatty acids [12]. This small fish is caught in the southern part of the Caspian Sea and a considerable amount of the catch is processed locally as canned foods or oil.

It seems that dietary supplementation with C. grimmi oil as a safe material may result in producing less-potent $\mathrm{PGs}$, therefore, it may be beneficial in controlling symptoms of dysmenorrhoea. This study was done to investigate the role of dietary supplementation with C. grimmi oil on symptoms of dysmenorrhoea in young girls.

\section{Methods}

Young women with dysmenorrhoea were followed up in this single-centre, double-blind, randomized, placebocontrolled, 6 cycle crossover study. All the participants signed consent forms. The study was conducted according to the principles of the Declaration of Helsinki and approved by Babol University of Medical Sciences ethics committee.

A total of 38 girls aged $18-22$ years, all students at Babol University of Medical Sciences, were randomly selected from a total of 1200 female students to participate in this study, which was carried out between March 2006 and November 2007. Sample size was determined based on the literature [13] and our previous study on different drugs for treating dysmenorrhoea in adolescents (A.A. Moghadamnia et al., unpublished report). Two of those selected indicated they did not wish to participate, leaving a sample of 36 . Eligibility criteria included: age $16-22$ years, negative serum $\beta$-HCG, gynaecologic examination within 1 year, suffering from dysmenorrhoea, having regular menstrual cycles, having no other health problems (according to their medical history), and low dietary fish intake (not more than twice per month). The participants were requested to complete a detailed questionnaire assessing their menstrual symptoms.

Fish oil was obtained from the C. grimmi autumn catch and the polyunsaturated fatty acids were measured. The oil was formulated in a suitable emulsion form. The formulation was based on fish oil, vitamins and natural orange juice, which masks the unpleasant smell of the oil. Each $15 \mathrm{~mL}$ of the emulsion contained $2.52 \mathrm{~g}$ infiltrated fish oil (with $755 \mathrm{mg}$ omega-3 fatty acid: $550 \mathrm{mg}$ eicosapentaenoic acid and $205 \mathrm{mg}$ decosahexaenoic acid), 4000 units vitamin $A, 400$ units vitamin $D$, 10 units vitamin $\mathrm{E}$ and $25 \mathrm{mg}$ vitamin C. The placebo contained all the emulsion basic ingredients except for the C. grimmi fish oil. The daily supplement was $15 \mathrm{~mL}$, taken as a single dose starting at the beginning of the menstrual cycle and continued for 3 consecutive months. The dosage and the 3-month treatment period were selected based on previous studies $[13,14]$ with minor modifications to permit optimal incorporation of the omega- 3 fatty acid in the phospholipids of the endometrial cell membranes.

The girls were randomly assigned to 1 of 2 schedules. In Group A, 18 girls received fish oil during the first 3 months, followed by placebo for another 3 months. In Group B, 18 girls started with placebo and switched to fish oil. All patients were given a bottle containing $200 \mathrm{~mL}$ emulsion (drug or placebo) and every bottle was specially encoded. Bottles were replaced as they ran out over the course of the study.

Efficacyand tolerability assessments: Patients were instructed to record their exact overall data of menstrual symptoms (pain, headache, etc.) based on a visual analogue scale (VAS) [15]. At the initial evaluation, severity of dysmenorrhoea was measured by VAS. For this evaluation, a $100 \mathrm{~mm}$ line was used to represent the range of the patient's options on degree of menstrual pain (extreme left indicated absence of pain and extreme right indicated worst possible). A score of 1-50 was considered mild pain, 51-80 moderate pain and $81-100$ severe pain [16]. All VAS data from each of the treatment groups (crossover arms of the study) were separately assessed and are given as mean VAS.

At the end of each month, the girls were asked to assess 2 main symptoms, abdominal pain and low back pain, on a 5-category scale ( $0=$ none, $1=$ slight, 2 $=$ mild, $3=$ moderate, $4=$ severe) $[15]$. 
When menstrual pain occurred, participants were allowed to use 1 dose of ibuprofen $400 \mathrm{mg}$ as a rescue medication while continuing with the experimental protocol. Maximum pain intensity and pain relief were assessed just before use of rescue medication. At the end of every month the girls were asked to report side-effects and record the amount of ibuprofen consumed during the menstrual period.

At the end of the study (6 months) the treatment protocol was decoded and the girls were requested to rate their cumulative degree of satisfaction with alleviation of dysmenorrhoea following each 3 months of treatment (placebo or oil) on a 5-category Likert scale (0 = strongly dissatisfied, 1 = dissatisfied, 2 = uncertain, 3 = satisfied, $4=$ strongly satisfied) [15].

\section{Data collection and analysis}

Data were listed and summarized in separate sheets and comparison between and within groups was made. The last scores before medication were used for all time points after medication. Comparisons of fish oil group with placebo (between-group analysis) were done using the Mann-Whitney U-test for unpaired data of menstrual symptoms. Comparisons among groups on data from the first and second 3-month regimens (within group analysis) were performed separately using the Wilcoxon test to account for individual differences in baseline scores, scores while receiving placebo, and scores while receiving fish oil. Dependent categorical outcomes of degree of satisfaction with alleviation of dysmenorrhoea were represented as frequency percentage and analysed by chi-squared, Fisher exact test.

The number of rescue doses of ibuprofen was analysed by Student $t$-test with factors for treatment and period and total number of doses; fish oil and placebo groups were compared separately using the repeated-measures test. The significance level was set at $P<0.05$.

\section{Results}

A total of 36 patients participated in this study. They all adhered to the entire 6-month study protocol and were included in the final analysis. The mean age of the 36 girls who were enrolled in the study was 20.7 [standard deviation (SD) 1.5] years, with mean time postmenarche 4.8 (SD 1.2) years. Mean body mass index (BMI) was 22.0 (SD 2.4) $\mathrm{kg} / \mathrm{m}^{2}$. Mean VAS score for the girls at initiation was 58.9. None of the participants had ever had sexual intercourse. Table 1 summarizes details of the 2 study groups.

Thirty-six girls completed the study. There was no significant difference in patients' characteristics between the 2 groups at the beginning $(P<0.05)$. With the exception of 2 reports of unpleasant taste of the emulsion, no adverse effects were reported during the whole 6 months study period.

\section{Between-group VAS data analysis (Mann-Whitney test)}

The VAS scores of the 2 groups at the beginning of the study were not statistically different: fish oil 57.2, placebo $61.0(P=0.14)$. Evaluation of the scores from both groups revealed a statistically significant reduction after 3 months supplementation with C. grimmi oil compared with placebo [20.9 (end of month 3 on fish oil); 61.8 (end of month 3 on placebo $)(P<0.001)]$.

\section{Within group VAS data analysis (Wilcoxon test)}

There was no a significant trend of improvement in menstrual symptoms with placebo treatment (VAS for total placebo group: 58.8 (SD 14.0) compared with VAS at the beginning of the study: 61 (SD 12.1) $(P=0.19)$. However, there was significant difference between the VAS score after treatment with C. grimmi oil compared with the beginning of the study (VAS for total fish oil group: $20.9(\min 8.3, \max 30.9)$ compared with VAS at beginning of

\begin{tabular}{|c|c|c|}
\hline Variable & Mean & SD \\
\hline \multicolumn{3}{|l|}{ Age (years) } \\
\hline Group A & 20.8 & 1.6 \\
\hline $\begin{array}{l}\quad \text { Group B } \\
\text { Age at first } \\
\text { menstruation } \\
\text { (years) }\end{array}$ & 20.8 & 1.4 \\
\hline Group A & 16.0 & 0.6 \\
\hline Group B & 15.6 & 0.6 \\
\hline \multicolumn{3}{|l|}{$B M I\left(\mathrm{~kg} / \mathrm{m}^{2}\right)$} \\
\hline Group A & 22.4 & 2.7 \\
\hline Group B & 21.7 & 1.9 \\
\hline
\end{tabular}

Study group $A(\mathrm{n}=18)$ : fish oil consumed during first 3 months followed by 3 months placebo. Study group B $(\mathrm{n}=18)$ : placebo consumed during first 3 months followed by 3 months fish oil.

$S D=$ standard deviation $; B M I=$ body mass index .

study: $57.2(\min 33.3, \max 70.8),(P$ $<0.0001)$.

The mean VAS scores for dysmenorrhoea at baseline (beginning of study) and at the end of the 3-month treatment with fish oil and placebo are shown in Figure 1. For better comparison, data obtained from each arm of the cross-over design is depicted separately. Overall, there was a significant difference between treatment with placebo and treatment with placebo fish oil $(P$ $<0.0001)$. There was no significant difference within the treatment groups.

\section{Abdominal and low back pain symptoms}

The chi-squared test was used to evaluate the intensity of abdominal and low back pain. There was a significant reduction in pain in the group receiving fish oil at the end of months 2 and 3 of the study (Table 2). There was no significant order effect or treastmentorder interaction when data of the group receiving placebo first and data for the group receiving fish oil first were compared.

\section{Rescue medication (ibuprofen 400) consumption}

The mean amount of ibuprofen consumed during the menstrual period as 


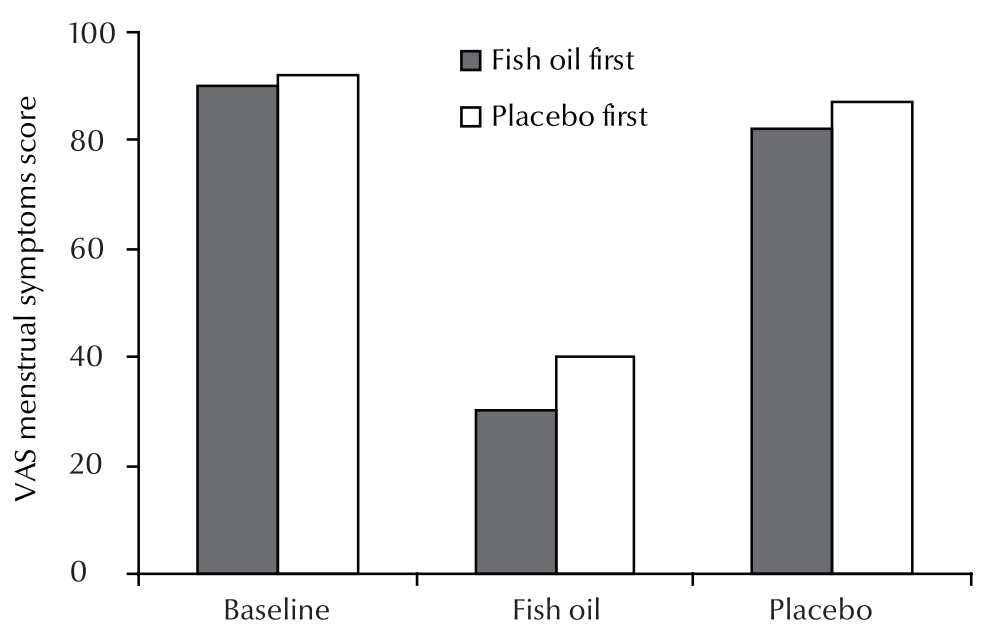

Figure 1 Mean visual analogue scale (VAS) scores for symptoms of dysmenorrhoea at baseline and at the end of the treatment period with fish oil or placebo. These data are shown for each arm of study in a cross-over design; ( $n=18$ in each group). Comparison of mean VAS scores for fish oil and placebo groups at 3 and 6 months showed significant difference $(P<0.0001)$.

rescue medication was significantly less while the girls were taking C.grimmi oil than during intake of placebo (3.0 (SD 2.5) tablets vs. 20.8 (SD 3.6) tablets; $P$ $<0.0001,95 \%$ CI: $13.2-17.4)$.

\section{Degree of satisfaction}

When girls were asked to rate the effectiveness of treatment with fish oil on a 5 - point Likert scale $(0=$ strongly dissatisfied, $1=$ dissatisfied, $2=$ uncertain, 3 = satisfied, $4=$ strongly satisfied), $97.2 \%$ rated it 3 or $4(P<0.001$, chi squared, Fisher's exact test) (Table 3$)$. As a consequence of the study more than $80 \%$ of the girls stated that they would like to increase their fish intake.

\section{Discussion}

In the present study we evaluated the effect of anchovy (kilka) fish oil supplement over a 3-month study period on primary dysmenorrhoea. This study showed that dietary supplementation with C. grimmi oil containing omega-3 poly-unsaturated fatty acid was effective in alleviating the symptoms of dysmenorrhoea in girls. The consumption of fish oil significantly reduced menstruation disorders such as abdominal pain and low back pain and significantly reduced the need for rescue NSAID medication. The protective role of the fish oil may be due to its omega- 3 fatty acid content $[10,17]$.

The majority of dysmenorrhoea in adolescents is primary (or functional), is associated with a normal ovulation cycle, with no pelvic pathology, and has a clear physiologic etiology [5,18]. After the onset of progesterone withdrawal before menstruation, a cascade of PGs and leukotrienes (LTs) is initiated in the uterus. The inflammatory response, which is mediated by these PGs and LTs produces both cramps and systemic symptoms such as nausea, vomiting, bloating and headache.

It is reported that with the dietary supplements there is a greater introduction of omega-3 fatty acids, which become incorporated in the phospholipids of the cell membrane [19]. The marked effect of omega-3 fatty acids dietary supplementation likely results from a build-up of less-potent PGs and LTs. There are many reports indicating that increasing dietary omega-3 fatty acid intake leads to increased incorporation of the acid into the cell wall phospholipids $[9,19]$. During menstruation, this fatty acid competes with the omega- 6 fatty acids for production of PGs and $\operatorname{LTs}[19,20]$.

As a result of fish oil supplementation, more prostaglandins of the third series (PGE3, PGI3 and thromboxane A3) are produced during menstruation $[10,13]$. In the uterus this production of less potent PGs likely results in decreased myometrial contractions and uterine vasoconstriction, leading to less ischaemia and less pain. These effects could be correlated to a suppression of the proliferation of uterine intimal smooth muscle cells as a result of inhibition of the production of paracrine growth factors such as platelet-derived growth factor [21] or to an increase in the sensitivity of the uterus to the relaxing effects of $\beta$-adrenergic catecholamines [19]. The reduction of the systemic symptoms seems also to be due to the production of less-powerful LTs, like those of the fifth series [18,22]. Our data support this hypothesis that dietary C. grimmi oil supplementation (omega-3 fatty acids) [12] can exert a protective role on menstrual pain and dysmenorrhoeal symptoms such as low back pain, abdominal pain and, to some degree, headache, etc. The girls who received placebo had menstrual pains more frequently compared with the fish oil-treated group and these data are in agreement with the results of previous studies with fish oil $[13,19]$. There is also some evidence supporting the role of PGs and LTs in migraine [23].

Some girls taking placebo required significantly more rescue medication (ibuprofen $400 \mathrm{mg}$ ) than those taking fish oil. This finding is consistent with some other studies on dysmenorrhoea $[8,24]$. Furthermore, the fish oil was well tolerated by the participants.

In the clinical trial, there may be some limitations. The formulation and preparation of the oil emulsion was expensive. The long duration of the study 


\begin{tabular}{|c|c|c|c|c|c|c|c|c|}
\hline \multirow[t]{2}{*}{ Treatment group/pain level } & \multicolumn{2}{|c|}{ Before treatment } & \multicolumn{2}{|c|}{ End of 1st month } & \multicolumn{2}{|c|}{ End of 2nd month } & \multicolumn{2}{|c|}{ End of 3rd month } \\
\hline & No. & $\%$ & No. & $\%$ & No. & $\%$ & No. & $\%$ \\
\hline & \multicolumn{8}{|c|}{ Abdominal pain } \\
\hline \multicolumn{9}{|l|}{ Placebo } \\
\hline No pain & 0 & 0.0 & 0 & 0.0 & 0 & 0.0 & 0 & 0.0 \\
\hline Slight & 0 & 0.0 & 1 & 5.6 & 0 & 0.0 & 0 & 0.0 \\
\hline Mild & 3 & 16.7 & 0 & 0.0 & 0 & 0.0 & 0 & 0.0 \\
\hline Moderate & 15 & 83.3 & 16 & 88.9 & 6 & 33.3 & 1 & 5.6 \\
\hline Severe & 0 & 0.0 & 1 & 5.6 & 12 & 66.7 & 17 & 94.4 \\
\hline \multicolumn{9}{|l|}{ Fish oil } \\
\hline No pain & 0 & 0.0 & 0 & 0.0 & 0 & 0.0 & 8 & 44.5 \\
\hline Slight & 0 & 0.0 & 1 & 5.6 & 14 & 77.8 & 10 & 55.6 \\
\hline Mild & 2 & 11.0 & 5 & 27.8 & 4 & 22.2 & 0 & 0.0 \\
\hline Moderate & 16 & 88.9 & 12 & 66.7 & 0 & 0.0 & 0 & 0.0 \\
\hline Severe & 0 & 0.0 & 0 & 0.0 & 0 & 0.0 & 0 & 0.0 \\
\hline \multirow[t]{2}{*}{ P-value } & \multicolumn{2}{|c|}{0.50} & \multicolumn{2}{|c|}{0.087} & \multicolumn{2}{|c|}{$<0.001$} & \multicolumn{2}{|c|}{$<0.0001$} \\
\hline & \multicolumn{8}{|c|}{ Low back pain } \\
\hline \multicolumn{9}{|l|}{ Placebo } \\
\hline No pain & 0 & 0.0 & 2 & 11.1 & 1 & 5.6 & 1 & 5.6 \\
\hline Slight & 2 & 11.9 & 4 & 22.2 & 2 & 11.1 & 3 & 16.7 \\
\hline Mild & 0 & 0.0 & 11 & 61.1 & 6 & 33.3 & 6 & 33.3 \\
\hline Moderate & 5 & 27.8 & 1 & 5.6 & 9 & 50.0 & 8 & 44.4 \\
\hline Severe & 11 & 61.1 & 0 & 0.0 & 0 & 0.0 & 0 & 0.0 \\
\hline \multicolumn{9}{|l|}{ Fish oil } \\
\hline No pain & 0 & 0.0 & 0 & 0.0 & 0 & 0.0 & 10 & 55.6 \\
\hline Slight & 1 & 5.6 & 5 & 33.3 & 11 & 61.1 & 4 & 22.2 \\
\hline Mild & 1 & 5.6 & 5 & 27.8 & 7 & 38.9 & 2 & 11.1 \\
\hline Moderate & 7 & 38.9 & 7 & 38.9 & 0 & 0.0 & 1 & 5.6 \\
\hline Severe & 9 & 50.0 & 0 & 0.0 & 0 & 0.0 & 1 & 5.6 \\
\hline P-value & \multicolumn{2}{|c|}{0.189} & \multicolumn{2}{|c|}{0.056} & \multicolumn{2}{|c|}{$<0.001$} & \multicolumn{2}{|c|}{$<0.003$} \\
\hline
\end{tabular}

may bother the subjects, and there is a possibility that the unpleasant taste of the fish oil may be a factor in loss to follow-up. However, in this study this did not occur; all participants completed the experiments.

It should be emphasized that patient satisfaction for relieving symptoms and the significant reduction in pain intensity using the fish oil promises this treatment as a very remarkable and easy to use remedy (as a food supplement) to help women with dysmenorrhoea. We propose to continue this research, widening the quantity of the data studied while investigating a wider range

\begin{tabular}{|c|c|c|c|c|c|}
\hline \multicolumn{6}{|c|}{$\begin{array}{l}\text { Table } 3 \text { Satisfaction with effectiveness of treatment with fish oil in comparison to } \\
\text { placebo on a 5-point Likert scale (subjective opinion) after } 3 \text { months treatment }\end{array}$} \\
\hline Treatment group & $\begin{array}{c}\text { Strongly } \\
\text { dissatisfied }\end{array}$ & Dissatisfied & Uncertain & Satisfied & $\begin{array}{l}\text { Strongly } \\
\text { satisfied }\end{array}$ \\
\hline Placebo (\%) & 67.6 & 25.0 & 7.4 & 0.0 & 0.0 \\
\hline Fish oil (\%) & 0.0 & 0.9 & 6.5 & 43.5 & 49.1 \\
\hline
\end{tabular}

$\mathrm{P}<0.001$ (chi-squared, Fisher exact test).

of foodstuffs to confirm these relationships and clarify any ambiguities.

\section{Acknowledgement}

This study was supported by a grant from the Research Department at Babol University of Medical Sciences.

The authors are indebted to Dr Moaoodi (Head of Nooshdaroo Darya Co., Babolsar, Islamic Republic of Iran) for her help in preparation of the fish oil. We thank Dr Zabihi for his skilful editing of the manuscript. We also thank the entire group of girls who participated in and completed the study. 


\section{References}

1. Dawood MY. Nonsteroidal antiinflammatory drugs and reproduction. American journal of obstetrics \& gynecology, 1993, 169(5):1255-65

2. Deligeoroglou E. Dysmenorrhea. Annals of the New York Academy of Science, 2000, 900:237-44.

3. Klein JR, Litt IF. Epidemiology of adolescent dysmenorrhea. Pediatrics, 1981, 68(5):661-4.

4. O'Connell K, Davis AR, Westhoff C. Self-treatment patterns among adolescent girls with dysmenorrhea. Journal of pediatric and adolescent gynecology, 2006, 19(4):285-9.

5. Alvin PE, Litt IF, Current status of the etiology and management of dysmenorrhea in adolescence. Pediatrics, 1982, 70(4):51625.

6. Bieglmayer $\mathrm{C}$ et al. Concentrations of various arachidonic acid metabolites in menstrual fluid are associated with menstrual pain and are influenced by hormonal contraceptives. Gynecological endocrinology, 1995, 9(4):307-12.

7. Owen PR. Prostaglandin synthetase inhibitors in the treatment of primary dysmenorrhea. Outcome trials reviewed. American journal of obstetrics \& gynecology, 1984, 148(1):96-103.

8. Mehlisch DR, Ardia A, Pallotta T. Analgesia with ibuprofen arginate versus conventional ibuprofen for patients with dysmenorrhea: A crossover trial. Current therapeutic research, 2003, 64(6):327-37.

9. Hansen HS, Olsen SF. Dietary (n-3)-fatty acids, prostaglandins, and prolonged gestation in humans. Progress in clinical and biological research, 1988, 282:305-17.

10. Deutch B. Menstrual pain in Danish women correlated with low n-3 polyunsaturated fatty acid intake. European journal of clinical nutrition, 1995, 49(7):508-16.

11. Lee TH et al. Effects of exogenous arachidonic, eicosapentaenoic, and docosahexaenoic acids on the generation of 5-lipoxygenase pathway products by ionophore-activated human neutrophils. Journal of clinical investigation, 1984, 74(6):1922-33.

12. Jafroodi H, Khatami M. [Gas chromatography identification of fatty acids in Caspian Sea Anchovy fish oill. North Shilat, 1995, 9:36-44 (in Farsi).
13. Harel Z et al. Supplementation with omega-3 polyunsaturated fatty acids in the management of dysmenorrhea in adolescents. American journal of obstetrics \& gynecology, 1996, 174(4):1335-8.

14. Schmidt EB et al. n-3 polyunsaturated fatty acid supplementation (Pikasol) in men with moderate and severe hypertriglyceridaemia: a dose-response study. Annals of nutrition \& metabolism, 1992, 36(5-6):283-7.

15. Juang $\mathrm{CM}$ et al. Impact of pregnancy on primary dysmenorrhea. International journal of gynaecology and obstetrics, 2006, 92(3):221-7.

16. Vercellini $\mathrm{P}$ et al. Endometriosis and pelvic pain: relation to disease stage and localization. Fertility and sterility, 1996, 65(2):299-304.

17. Kennedy S. Primary dysmenorrhoea. Lancet, 1997, 349(9059):1116.

18. Benedetto C. Eicosanoids in primary dysmenorrhea, endometriosis and menstrual migraine. Gynecological endocrinology, 1989, 3(1):71-94.

19. Balbi $\mathrm{C}$ et al. Influence of menstrual factors and dietary habits on menstrual pain in adolescence age. European journal of obstetrics \& gynecology and reproductive biology, 2000, 91(2):143-8

20. $\mathrm{Wu} \mathrm{MH}$ et al. Endometriosis: disease pathophysiology and the role of prostaglandins. Expert reviews in molecular medicine, 2007. 9(2):1-20.

21. Fox PL, DiCorleto PE. Fish oils inhibit endothelial cell production of platelet-derived growth factor-like protein. Science, 1988, 241(4864):453-6.

22. Penland JG, Johnson PE. Dietary calcium and manganese effects on menstrual cycle symptoms. American journal of obstetrics \& gynecology, 1993, 168(5):1417-23.

23. Vapaatalo $\mathrm{H}$. Tolfenamic acid and migraine-aspects on prostaglandins and leukotrienes. Pharmacology \& toxicology 1994 75(Suppl. 2):76-80.

24. Daniels SE, Torri S, Desjardins PJ. Valdecoxib for treatment of primary dysmenorrhea. Journal of general internal medicine, 2004, 20:62-7. 